\title{
Rain area delineation by means of multispectral cloud characterization from satellite
}

\author{
F. Torricella, E. Cattani, and V. Levizzani \\ National Research Council, Institute of Atmospheric Sciences and Climate, Bologna, 40129, Italy \\ Received: 25 February 2008 - Revised: 17 March 2008 - Accepted: 15 May 2008 - Published: 20 June 2008
}

\begin{abstract}
The identification of precipitation areas by microwave based rain algorithms can be improved by means of cloud classification schemes based on multispectral observations. Several recent studies have demonstrated the potential of cloud microphysical and optical characterization for the improvement of passive microwave rain estimates, especially in detecting likely precipitating pixels over land. The multispectral sensing capabilities of MODIS onboard Aqua are exploited to characterize the cloudy scenario, using a twofold approach: a) an RGB technique to qualitatively identify the different cloud systems on the basis of the combination of radiances measured in three selected channels, and b) a quantitative description of cloud top in terms of optical thickness $(\tau)$, effective radius $\left(\mathrm{R}_{e}\right)$ and top temperature $\left(\mathrm{T}_{c}\right)$. The information gathered by the multispectral analysis of the cloud field from MODIS is contrasted with the rain intensity at the ground as derived from the AMSR-E operational algorithm, to assess the statistical relationships between microphysical parameters and the rain intensity for such nearly simultaneous and co-located observations.
\end{abstract}

\section{Introduction}

The identification of precipitation areas by microwave based rain algorithms can be improved by means of cloud classification schemes based on multi-spectral observations. A major requirement of a satellite based precipitation product for operational applications (hydrology, nowcasting) is the timely generation of estimates for the region of interest. This requirement suggests the use of geostationary data to fill time and space gaps in between the intermittent microwave (MW) based rain estimates. Based on sensing capabilities of last



Correspondence to: $\mathrm{F}$. Torricella (f.torricella@isac.cnr.it) generation multi-spectral instruments (e.g., SEVIRI, Spinning Enhanced Visible and Infrared Imager, and MODIS, Moderate Resolution Imaging Spectroradiometer), several algorithms have been developed to combine these two different satellite observations of the cloud-rain field, i.e. multispectral and passive microwave (see some of them at the International Precipitation Working Group (IPWG) web site: http://www.isac.cnr.it/ ipwg/algorithms.html).

Likewise, precipitating indices from VIS-NIR-IR (visible, near infrared and infrared) spectral features showing the highest correlation with precipitation can be tuned by means of co-located ground measurements of rain intensity (gathered from gauge or radar networks) and can be used to derive the likelihood of precipitation (Thoss et al., 2001).

In this work we assess the relationship between the cloud top microphysical parameters from operational MODIS products, and the rain intensity at the ground as derived from the AMSR-E (Advanced Microwave Scanning RadiometerEarth Observing System) operational algorithm. Both instruments are state-of-the-art in their own field (multi-spectral observation of the cloud field and MW conical scanning for rain retrieval), and they simultaneously observe the same region. The swaths of the two instruments are different so that direct comparison is restricted to the narrowest AMSRE swath $(1445 \mathrm{~km}$ across track compared to $2330 \mathrm{~km}$ of MODIS). Both sensors outperform other similar instruments as to spatial ground resolution and the adopted operational algorithms are very mature. We can thus state that the correlation derived in the present case can be considered optimal as to the application of the proposed combined analysis based on operational products.

\section{The study period}

Precipitation events occurred in the Mediterranean region (between $35^{\circ} \mathrm{N}$ and $52^{\circ} \mathrm{N}$, and $9^{\circ} \mathrm{W}$ and $22^{\circ} \mathrm{E}$ ) during the

Published by Copernicus Publications on behalf of the European Geosciences Union. 
Table 1. Main features of the adopted day microphysical noninverted display mode.

\begin{tabular}{llll}
\hline Beam & Channels & Range & Gamma \\
\hline RED & REFL $(0.8)$ & {$[0,1]$} & 1 \\
GREEN & REFL $(3.7)$ & {$[0,0.25]$} & 1.5 \\
BLUE & BT(11) & {$[203,323][\mathrm{K}]$} & 1 \\
\hline
\end{tabular}

Table 2. Number of observations (pixels) of the two instruments during the analysis period (from 1 to 15 June 2007).

\begin{tabular}{lr}
\hline & \# pixels \\
\hline MODIS & $\mathbf{2 7 6 0 4 6 2 0}$ \\
over land & 8031846 \\
over the sea & 3174185 \\
over the coast & 84552 \\
cloudy & 11290583 \\
water clouds & 5505942 \\
ice clouds & 5784641 \\
AMSR-E & $\mathbf{9 3 6 1 0 3}$ \\
rainy & 49000 \\
convective rain & 36510 \\
bad pixels & 491255 \\
\hline
\end{tabular}

first 15 days of June 2007 were analyzed. The period was characterized by very unstable weather, in particular over Italy. The most severe events took place in the first decade of the month, when a low-pressure system located over centralSouth Europe associated with cold air at high levels, fostered heavy thunderstorms and downpours on the 1st and 2nd. On 7 June and, again, on 11 and 13, the thunderstorms over the Italian peninsula intensified, with very high cumulated precipitation values and a strong lightning activity.

\section{Instruments and data}

The analysis of the relationship between precipitation intensity and cloud optical and microphysical characteristics was conducted by exploiting the MODIS cloud products (Platnick et al., 2003) and the AMSR-E global swath rain product distributed by the National Snow and Ice Data Center (Wilheit et al., 2003). Both sensors are on board NASA's Aqua satellite thus ensuring simultaneous co-located observations of the same scenes.

The MODIS cloud products of thermodynamical phase, effective radius ( $\mathrm{R}_{e}$ in $\left.\mu \mathrm{m}\right)$ and optical thickness $(\tau)$, at the spatial resolution of $1 \times 1 \mathrm{~km}^{2}$, were used for the characterization of cloudy scenes.

The AMSR-E rain swath product (AE_Rain) contains instantaneous measurements of rain rate and rain type (con- vective vs. stratiform) generated from brightness temperatures by means of the Goddard Space Flight Center (GSFC) Profiling algorithm (GPROF). Over oceans, the rainfall algorithm is based on a Bayesian retrieval scheme while over land it consists of a regression of scattering signals to surface rainfall (Wilheit et al., 2003). The ocean retrieval relies primarily on the emission signal from the rain drops themselves while the land retrieval uses solely the scattering at $89 \mathrm{GHz}$ from precipitation sized ice particles at and above the freezing level. The two approaches are needed due to the vastly different surface emissivities and the resulting differences in the sensor information content over ocean and land, respectively. The spatial resolution of the product is $5.4 \times 5.4 \mathrm{~km}^{2}$.

\section{Visual analysis}

A qualitative representation of the cloud field was achieved using the RGB technique (Rosenfeld and Lensky, 1998). The RGB is a method that provides a relatively simple rendering of multispectral satellite information for the quick interpretation of meteorological scenes. The optimum coloring of the RGB composites results from the proper selection of the satellite sensor channels and the enhancement of the individual colors. The channel selection must be driven by the particular phenomenon (low or high clouds, dust, smoke, etc.) to be detected or emphasized in the satellite image. At the same time, the proper color enhancement requires the conversion from radiances to brightness temperatures (IR channels) or reflectances (VIS/NIR channels), selection of the display mode (inverted or not inverted), stretching of the dynamic range of the satellite data, and gamma correction. The so-called day-microphysical scheme (Kerkmann et al., 2005) was adapted to the MODIS channels 16 (centered at $0.8 \mu \mathrm{m}$ ), $20(3.7 \mu \mathrm{m})$, and $31(11 \mu \mathrm{m})$ combined in non-inverted display mode (black corresponds to low signals and white to high signals). This RGB scheme is particularly suitable for the interpretation of cloudy scenes and is recommended to emphasize the presence of severe convection during daytime. According to this scheme the reflectances at $0.8 \mu \mathrm{m}$ (REFL(08)) are associated to the red beam. The VIS reflectances are sensitive to the optical thickness $(\tau)$ values, increasing with it. The NIR $(3.7 \mu \mathrm{m})$ reflectances (REFL(37)) depend on $\mathrm{R}_{e}$ values and are associated to the green beam and decrease with increasing $\mathrm{R}_{e}$. Finally, the brightness temperatures at $10.8 \mu \mathrm{m}(\mathrm{BT}(11))$ are a proxy for the surface temperature or the cloud top temperature $\left(\mathrm{T}_{c}\right)$ and are represented by blue shades. Table 1 reports the features of the adopted display scheme together with the channel recommended ranges and the associated gamma corrections. By using the described approach the maps (a) and (d) of Fig. 1 have been produced. Figure 1 is an example from 11 June of the co-located analysis, out of the 22 Aqua overpasses over the area during daytime (see also the next Section and Table 2). Even if this kind of method requires an interpretation 



Fig. 1. Example of co-located analysis for the Aqua overpass on June 11th, 12:30 UTC. On the second column zoom over the NordrheinWestfalen region. (a) and (d): RGB representation of the scenario. (b) and (e): optical thickness derived from MODIS. (c) and (f) rain intensity at the ground from AMSR-E (in dark grey missing or invalid data). Colour palettes: tau from 1 to 100, linear. Rain intensity: from 0.1 to $35 \mathrm{~mm} \mathrm{~h}^{-1}$, linear.

of the color shades, which is to some extent subjective and non-quantitative, it is apparent that in this case several categories of targets can be detected, namely: a) the deep precipitating clouds in bright red, characterized by high $\tau$ values (high red), large ice particle at the top (low green) and low $\mathrm{T}_{c}$ values (low blue); $\mathrm{b}$ ) thin cirrus with small ice particles or supercooled, thin water clouds in bright green (low red due to the small $\tau$, high green for the small $\mathbf{R}_{e}$, and medium to low blue for intermediate $T_{c}$ values); c) the vegetated surface in light blue, and d) the ocean in dark blue.

The maps (b) and (e) in Fig. 1 report the $\tau$ values retrieved from MODIS according to the included color palette. As specified in the next section, the cloud optical thickness is the parameter that better correlates with the rain intensity. The last row of Fig. 1 displays the rain intensity maps from the AMSR-E product and the red contour lines in (f) encompass 
(a)
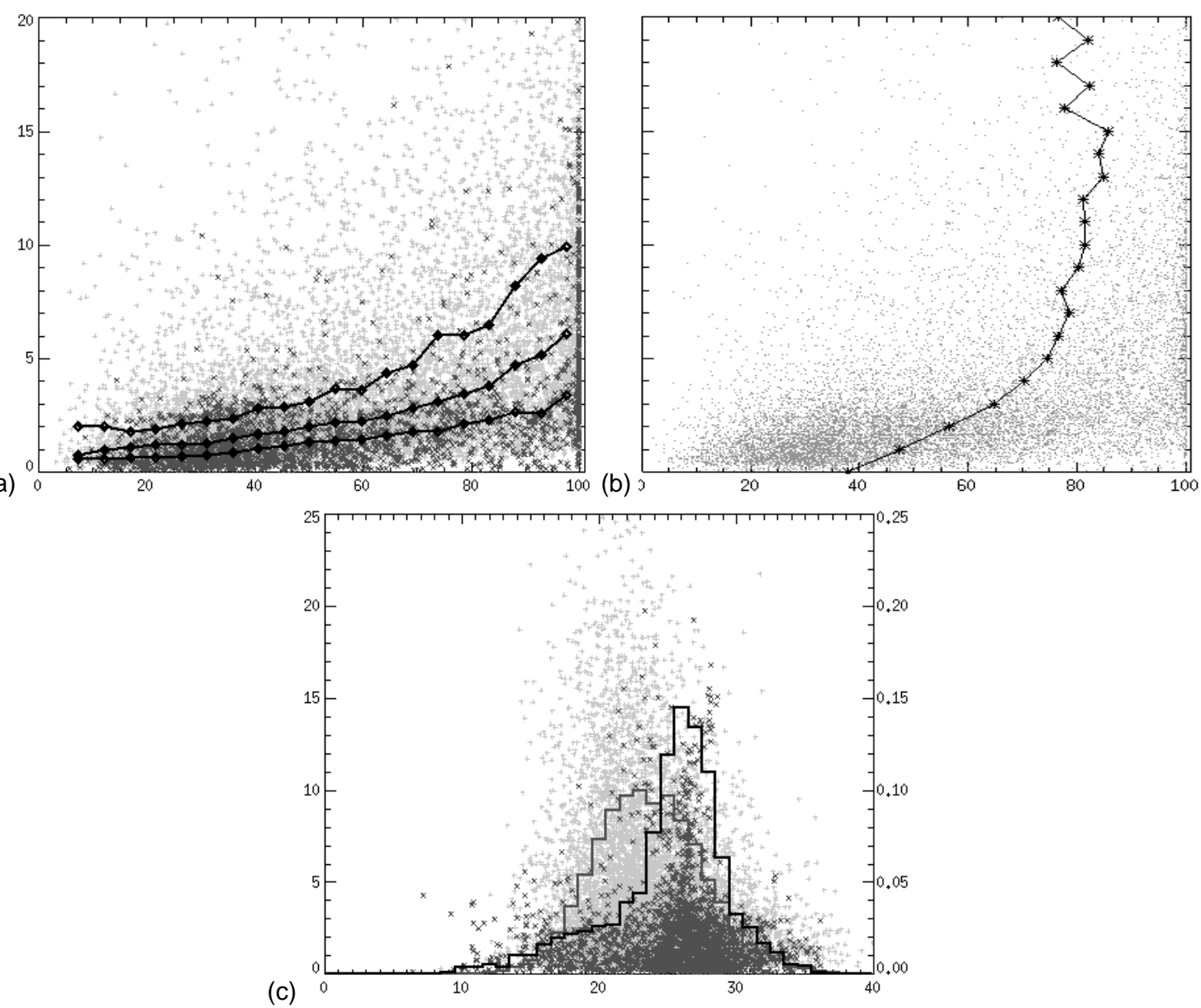

Fig. 2. Rain intensity at the ground as a function or $\tau$ (top) and $\mathrm{R}_{e}$ (bottom). Y axis: rain intensity in $\mathrm{mm} \mathrm{h}^{-1}$. $\mathrm{X}$ axis: optical thickness (a and $\mathbf{b}$ ); effective radius in $\mu \mathrm{m}$ (c). In (c) on the right y axis: frequency distribution.

the areas where MODIS detected an optical thickness greater than 40. Maps in the first column of Fig. 1 enclose the whole study area, while the second column contains the zoomed-in pictures of the northernmost rain feature, over the Nordrhein-Westfalen region (Germany). The visual inspection of the maps confirms the good correlation between the microphysical display (red convective areas) and the precipitation field. Yet, the rain features (c and f) appear more localized and structured than the cumulonimbus cloud revealed by the RGB display. Thick clouds $(\tau>40)$ nicely correspond to the area of significant rainfall (rain rate $>2 \mathrm{~mm} \mathrm{~h}^{-1}$ ).

\section{Statistical analysis}

To carry out quantitative comparisons, all the data from the 22 daytime Aqua overpasses were re-projected over a $0.1^{\circ} \times 0.1^{\circ}$ regular lat-lon grid covering the area. Table 2 summarizes the grand total figures of the analyzed data in terms of number of observations (pixels) of the two instruments. The most prominent aspect is the high number of bad AMSR-E pixels, i.e. the pixels discarded in the AMSRE product by the screening procedure of the algorithm or rejected because of other problems. Almost all the rejected pixels are over the land, so they have been probably discarded in the screening phase of the algorithm, deeming impossible to proceed to the rain retrieval due to the characteristics of the target. About two thirds of the bad pixels are detected as clear in our analysis, so they are truly irrelevant in the assessment of the rain retrieval. The remaining third part of bad pixels are nonetheless cloudy, and associated with significant optical thickness values (mean value $\sim 23$ ). In several cases they are clearly associated with nearby rain features detected by the algorithm. It would be worthy to re-process these cloudy pixels with the rain retrieval algorithm, but the present analysis based on operational products prevents this test. The pixels flagged as ambiguous retrieval (2256) were not included in the present analysis because they are associated with negative rain intensities.

More than $74 \%$ of rainy observations are classified as convective (i.e. they have a non zero component of convective 
precipitation). In Table 3 the statistics of grid points is given. Note that the percentages in column 3 (but the first three figures that refer to the total number) are computed considering only the cloudy grid points. Similarly the rainy pixels percentages (given in brackets) are computed with respect to the number of points of each category (e.g., the ice cloud points are 47316 that is $46 \%$ of cloudy mesh points; 12861 out of 47316 are rainy, the $27 \%$ ). The grid points are defined cloudy if more than $90 \%$ of the MODIS pixels falling in the grid point are classified as cloudy. For this reason the percentage of cloudy observations falls from $40 \%$ at the MODIS space scale, to $13 \%$ in the gridded analysis, in which only almost totally obstructed observations at the scale $0.1^{\circ} \times 0.1^{\circ}$ are considered cloudy. The number of land grid points is 2.8 times higher than the number of points over the sea, and rain is more probable ( $18 \%$ of cloudy grids are rainy over land vs $12 \%$ over the sea). Cloudy grid points mainly composed of frozen clouds are almost twice probable than water clouds. The most relevant figures of Table 3 (bold) reveal that only $0.6 \%$ of water clouds are detected as raining by the MW algorithm, while $27 \%$ of ice clouds are raining. This sharp but not unexpected result confirms that this kind of MW algorithm detects and gauges rain mainly when clouds have a frozen top. This is a well know problem of rain detection over the land, but the present analysis reveals the same bias of the rain algorithm also over the sea. Warm topped clouds (i.e. clouds with liquid water phase detected at the top) have negligible probability to be detected as raining by the AMSR-E operational algorithm for the analyzed period. Further analysis of the large number of cloudy, optically thick observations discarded by the rain retrieval algorithm screening procedure is required.

\section{Comments and conclusions}

Figure 2a presents the scatter plot of rain intensity vs optical thickness for the gridded data. The plot contains only data for grid points identified as ice clouds. The data over land are represented in light grey while those over the sea are depicted in dark grey. The solid lines connecting diamonds represent the 75, 50 and 25 percentiles. Despite the large scatter in the data, there is a weak positive correlation between rain intensity and optical thickness. The value 100 is the maximum retrieved optical thickness while the maximum rainrate is $50 \mathrm{~mm} \mathrm{~h}^{-1}$. Only few grid points have rain intensity values greater than $25 \mathrm{~mm} \mathrm{~h}^{-1}$ and thus the y axis of the plots was cut to this value.

Further information can be gained from a binned analysis, i.e. all rain data are binned in intervals of $1 \mathrm{~mm} \mathrm{~h}^{-1}$ and the optical thickness values in these bins are averaged. The result of this analysis is illustrated in Fig. 2b. The main improvement is the much more visible trend in the data and the presence of a sort of threshold for initiating raining at $\tau=40$. The relationship is fairly smooth, at least up to $15 \mathrm{~mm} \mathrm{~h}^{-1}$.
Table 3. Number of grid points analyzed. In brackets the number of rainy points for each given subset.

\begin{tabular}{lrr}
\hline classification & \# mesh points & \% \\
\hline total & 797715 & 100 \\
rainy but clear & 4728 & 0.6 \\
cloudy & $102512(20789)$ & $13(20)$ \\
over the sea & $24991(3098)$ & $24(12)$ \\
over the land & $71426(12694)$ & $70(18)$ \\
water phase & $24301(144)$ & $24(\mathbf{0 . 6})$ \\
ice phase & $47316(12861)$ & $46(\mathbf{2 7})$ \\
coast contam. & 6080 & 5 \\
\hline
\end{tabular}

Then the curve seems to come to an asymptote, roughly corresponding to $\tau=90$.

As regards the correlation between the retrieved $\mathrm{R}_{e}$ values and the rain intensity, it seems that no clear correlation exists in the data (see Fig. 2, c panel). The rain distributions with respect to $\mathrm{R}_{e}$ show a broad spread with a mode value higher for points over the sea with respect to the distribution over the land.

Acknowledgements. The Authors gratefully acknowledge the support of the projects HSAF (EUMETSAT Satellite Application Facility on Support to Operational Hydrology and Water Management), RISKMED (an INTERREG III B Archimed project on Weather Risk Reduction for the Mediterranean), and ANTISTORM (Anthropogenic Aerosols Triggering and Invigorating Severe Storms, a European Commission NEST INSIGHT Project).

Edited by: A. Mugnai

Reviewed by: one anonymous referee

\section{References}

Kerkmann, J., Rosenfeld, D., and Bridge, G.: MSG interpretation guide. RGB IMAGES: PART IV, RGB Composites with channels 01-11 and their interpretation, http://oiswww.eumetsat.org/ WEBOPS/msg_interpretation/index.html, 2005.

Platnick, S., King, M. D., Ackerman, S. A., Menzel, W. P., Baum, B. A., Riédi, J. C., and Frey, R. A.: The MODIS cloud products: Algorithms and examples from Terra, IEEE Trans. Geosci. Remote Sens., 41, 459-473, 2003.

Rosenfeld, D. and Lensky, I. M.: Satellite-based insights into precipitation formation processes in continental and maritime convective clouds, Bull. Amer. Meteor. Soc., 79, 2457-2476, 1998.

Thoss, A., Dybbroe, A., and Bennartz, R.: The Nowcasting SAF Precipitating Clouds Products. Proceedings of the 2001 EUMETSAT Satellite Data User's Conference, Antalyia, Turkey, 1-5 October, 2001

Wilheit, T., Kummerow, C., and Ferraro, R.: Rainfall algorithms for AMSR-E, IEEE Trans. Geosci. Remote Sens., 41, 2, 204-214, 2003. 